Support' included the ability to get advice from experienced colleagues, and that topics covered in the sessions were not usually covered in training for GPs. Also, joining the sessions remotely was a frequently cited as a benefit and to be a productive use of time. Professional isolation was reduced and satisfaction was increased.

Conclusion Project ECHO is an ideal methodology for not only delivering education and advice to medical professionals but also as a mechanism for support in an isolated profession.

\section{P-201 INTRODUCING PROJECT ECHO TO SUPPORT END-OF- LIFE CARE EDUCATION IN PRIMARY CARE DURING A PANDEMIC}

Toni Flanagan, Jade Reberio, Gary Lee. St Giles Hospice, Lichfield, UK

10.1136/spcare-2021-Hospice.217

Project ECHO is an innovative tele-mentoring programme designed to create virtual communities of learners by bringing together health care providers and subject matter experts using videoconference technology, brief lecture presentations, casebased learning, fostering an 'all teach, all learn' approach. In April 2020 a six-month pilot of Project ECHO was commenced to support end-of -life care education in primary care as a response to the COVID-19 pandemic.

A scoping exercise was undertaken with the multidisciplinary primary care team across a defined geographical area. Following the scoping exercise a curriculum was devised. Speakers were arranged which included a palliative care medical consultant, a specialist pharmacist and speciality doctor who led the taught aspects of each of the six sessions drawing on their clinical expertise and previous teaching experience. The attendees had the opportunity to submit a case study for discussion during each ECHO session, the case studies were used to evoke discussion, promote shared learning and develop a community of practice. During the pandemic this format also created an opportunity for peer supervision and sharing of clinical knowledge and experience across a wider network of practitioners.

Considering the project took place during a pandemic there was $83 \%$ attendance from those that had booked onto the sessions. At the end of each session an instant poll was available to be completed by the attendees to evaluate the session. Attendees fed-back how valuable they found the sessions especially the opportunity to discuss case studies, share best practice and debrief during what has been a particularly difficult time for the primary care sector. The online format allowed more people to attend than would normally be achieved in face-to-face training. Due to the project's success further funding was agreed to extend the project beyond the original sixmonth pilot.

\section{P-202 CO-CREATING OUR CORE COMPETENCIES}

Sarah Ireland. St Margaret's Hospice, Somerset, UK

10.1136/spcare-2021-Hospice.218

Aims To develop a core competencies framework building on our values, review the organisational appraisal process and start defining career pathways. To use the framework as the basis for a different approach to performance and recruitment. Methods The principles framing the project were: What is the business need? How does the process support our value proposition? How does this process recognise high performance, improve retention and support potential talent?

The critical incident technique used consisted of a set of procedures for collecting direct observations of human behaviour in such a way as to facilitate their potential usefulness in solving practical problems, and developing broad psychological principles. The working group collected, reviewed and analysed more than 100 pieces of data; developed behavioural indicators based on the data, and then sense-checked the results with staff across the hospice. The working group included representatives from all departments of the hospice. Pilots were used to test the initial framework in interviews, performance conversations and appraisals.

Results The core competency framework was co-created between December 2019 and March 2020, signed off and implementation started on 1 April 2020 and created a behavioural baseline. A test, learn, adapt approach increased ownership. All staff have been introduced to the framework through live webinars enabling active engagement. Staff are using the new adaptive approach to performance after a period of testing. Core competencies are used in job adverts, job descriptions and appraisals. A bank of resources was created to support implementation including live webinars, leaflets and a self-assessment tool.

Conclusion There is a clear ownership by staff created by the inclusive process and an understanding of how core competencies can be used. Their feedback supports this:

- Encourages honesty and openness.

- Gives a focus to performance reviews.

- Relevant for all staff.

- Communicates expectations with respect to values and behaviours.

- Enables people to feel comfortable with what's expected of them.

\section{P-203 ABSTRACT WITHDRAWN}

\section{P-204 INCLUSION AND ENGAGEMENT - CREATING A BLACK ASIAN \& MINORITY ETHNIC STAFF NETWORK AT ST GEMMA'S HOSPICE}

Heather McClelland, Clare Dixon. St Gemma's Hospice, Leeds, UK

10.1136/spcare-2021-Hospice.219

Background St Gemma's Hospice in Leeds provides care and support for patients and families in a vibrant, multi-cultural city. Through community engagement work we have identified gaps and improved access to hospice services right across the communities of Leeds, but this is not reflected in our workforce. Like many hospices we have poor representation of Black, Asian and Minority Ethnic communities in the workforce, especially in clinical and education services. Supported by the Employee Engagement Group, the trustees, and Human Resources this year, we started a Black, Asian \& Minority Ethnic staff network aiming to: 